\title{
Protective effect of pyrrolidine dithiocarbamate on isoniazid/rifampicin-induced liver injury in rats
}

\author{
XUE HE ${ }^{1,2}$, YULIN SONG ${ }^{1}$, LI WANG $^{1,3}$ and JIANMING XU ${ }^{1}$ \\ ${ }^{1}$ Department of Gastroenterology, The First Affiliated Hospital of Anhui Medical University, Hefei, Anhui 230022; \\ ${ }^{2}$ Department of Gastroenterology, Affiliated Chaohu Hospital of Anhui Medical University, Hefei, \\ Anhui 238000; ${ }^{3}$ Department of Pediatrics, The First Affiliated Hospital of University \\ of Science and Technology of China, Hefei, Anhui 230022, P.R. China
}

Received April 9, 2019; Accepted October 1, 2019

DOI: $10.3892 / \mathrm{mmr} .2019 .10817$

\begin{abstract}
Isoniazid (INH) and rifampicin (RIF) continue to be first line anti-tuberculosis (TB) drugs. However, the use of these drugs is associated with hepatotoxicity. Nuclear factor- $\kappa \mathrm{B}(\mathrm{NF}-\kappa \mathrm{B})$ plays a crucial role in regulating immunity and inflammation. It has been reported that pyrrolidine dithiocarbamate (PDTC), an inhibitor of $\mathrm{NF}-\kappa \mathrm{B}$, exerts a hepatoprotective effect on acute and chronic liver damage. The aim of the present study was to explore the INH/RIF-induced protective effects and mechanisms of PDTC on liver injury. Rats were intragastrically administered INH $(50 \mathrm{mg} / \mathrm{kg} /$ day $)$ and RIF ( $50 \mathrm{mg} / \mathrm{kg} /$ day) daily for 28 days. PDTC ( $50 \mathrm{mg} / \mathrm{kg} /$ day) was intraperitoneally injected $2 \mathrm{~h}$ after the co-administration of INH and RIF to compare liver biochemical indicators in the serum, histopathological damage, NF- $\kappa \mathrm{B}$ activity, oxidative stress, hepatic mRNA expression of tumor necrosis factor (TNF)- $\alpha$, bile salt export pump (BSEP), and protein expression of BSEP. It was found that the inhibition of NF- $\kappa B$ activation by PDTC treatment markedly alleviated liver biochemical and histological injury, decreased oxidative stress and mRNA levels of TNF- $\alpha$, and prevented decreases in BSEP mRNA and protein expression induced by the co-administration of INH and RIF. Collectively, the present data suggested that INH/RIF-induced liver injury is dependent on the
\end{abstract}

Correspondence to: Professor Yulin Song, Department of Gastroenterology, The First Affiliated Hospital of Anhui Medical University, 218 Jixi Road, Hefei, Anhui 230022, P.R. China E-mail: ylsongcn@163.com

Abbreviations: INH, isoniazid; RIF, rifampicin; TB, tuberculosis; $\mathrm{NF}-\kappa \mathrm{B}$, nuclear factor- $\kappa \mathrm{B}$; PDTC, pyrrolidine dithiocarbamate; ALT, alanine aminotransferase; AST, aspartate aminotransferase; ALP, alkaline phosphatase; TBA, total biliary acid; TBIL, total bilirubin; DBIL, direct bilirubin; MDA, malondialdehyde; SOD, superoxide dismutase; BSEP, bile salt export pump; TNF- $\alpha$, tumor necrosis factor- $\alpha$; ROS, reactive oxygen species

Key words: isoniazid, rifampicin, liver injury, NF- $\kappa \mathrm{B}$, oxidative stress, TNF- $\alpha$, BSEP activation of $\mathrm{NF}-\kappa \mathrm{B}$. PDTC exerted a therapeutic effect on INH/RIF-induced liver injury by increasing BSEP expression, and exhibiting antioxidant and anti-inflammatory activities.

\section{Introduction}

Tuberculosis (TB) remains a major health problem world worldwide, accounting for 9.6 million new cases and 1.5 million mortalities annually (1). Although highly effective, isoniazid (INH) and rifampicin (RIF) combination therapy is associated with hepatotoxicity $(2,3)$. Hepatotoxicity is the most common serious complication of anti-TB therapy, and can range from asymptomatic elevation of serum transferases to hepatitis or hepatic failure (4). Previous studies in rats have shown that the hepatotoxicity of anti-TB drugs is associated with inflammatory infiltration, hepatocyte necrosis and fatty degeneration, as well as changes in serum biochemical markers (5-7). Although the exact mechanisms of INH and RIF-induced liver injury remain unclear, several mechanisms have been suggested, such as oxidative stress, lipid peroxidation, dose-related toxicity, genotyping-related toxicity and increased risk of toxic INH metabolites as a result of enzyme induction (2,3). Endogenous lipid peroxidation has been reported to be a primary factor driving the cytotoxic actions of INH and RIF (5). INH and RIF-mediated oxidative injury is generally attributed to the accumulation of reactive oxygen species (ROS), which has been indicated in cell signaling alterations, and can lead to mitochondrial dysfunction, damage to the cell membrane and apoptosis in hepatocytes (6). Antioxidants may therefore serve a protective role against INH-RIF-induced liver injury (7).

Nuclear factor $-\kappa \mathrm{B}(\mathrm{NF}-\kappa \mathrm{B})$ is a ubiquitous transcription factor that mediates immune and inflammatory responses, cell proliferation and apoptosis (8). Pyrrolidine dithiocarbamate (PDTC), an antioxidant and potent inhibitor of $\mathrm{NF}-\kappa \mathrm{B}$, has previously been shown to exert extensive anti-inflammatory and antioxidant effects in rat models of liver cirrhosis (9), immunological liver injury (10), liver failure (11) and cholestatic liver injury (12). Although it has been suggested that PDTC can have hepatoprotective effects and therapeutic value in various types of liver disease, its effects on anti-TB drug-induced liver injury are yet to be elucidated. 
The aim of the present study was to explore the potential protective effects of PDTC on INH/RIF-induced liver injury. The potential mechanisms underlying its therapeutic effects were also investigated.

\section{Materials and methods}

Animals and experimental design. Male Sprague-Dawley rats (150-180 g; specific pathogen-free grade) were obtained from the Experimental Animal Center of Anhui Medical University (Hefei, China) and housed in rooms with a maintained temperature of $22-25^{\circ} \mathrm{C}$ and humidity of $50 \pm 5 \%$ under a 12 -h light-dark cycle, and provided food and water ad libitum. Rats were acclimatized for 1 week prior to the initiation of experiments. The animal experiments were approved by the Animal Care and Use Committee of Anhui Medical University. A total of 24 rats were randomly assigned to 3 groups ( $\mathrm{n}=8 /$ group) and treated for 28 consecutive days as follows: Rats in the INH + RIF and PDTC groups were intragastrically administered INH $(50 \mathrm{mg} / \mathrm{kg} / \mathrm{day})$ and RIF $(50 \mathrm{mg} / \mathrm{kg} / \mathrm{day}$; Yan'an Pharmaceutical Co., Ltd.) following $3 \mathrm{~h}$ of abrosia $(13,14)$. Control rats were intragastrically treated with an equivalent volume of $0.9 \%$ sodium chloride. Additionally, the PDTC group received $50 \mathrm{mg} / \mathrm{kg} /$ day PDTC (Merck $\mathrm{KGaA})$ via an intraperitoneal injection $2 \mathrm{~h}$ following the co-administration of INH and RIF $(10,15,16)$. The rats in the control and model groups were intraperitoneally injected with the equivalent volume of $0.9 \%$ sodium chloride (14). RIF and INH were solubilized in $1 \%$ sodium carboxymethylcellulose and $0.9 \%$ sodium chloride, respectively. PDTC initially was dissolved in DMSO at $10 \mathrm{mg} / \mathrm{ml}$ and then diluted by $0.9 \%$ sodium chloride to $50 \mathrm{mg} / \mathrm{ml}$. Rats were anesthetized by an intraperitoneal injection of sodium pentobarbital $(50 \mathrm{mg} / \mathrm{kg})$ the morning following the final drug treatment. Blood was collected into microtubes from the abdominal aorta. Rat livers were rapidly excised, leaving the left lobe of the liver in $10 \%$ neutral formalin-fixed buffer for histological analysis. The remaining livers were snap-frozen and stored in a liquid nitrogen container until required (17). Then, the rats were sacrificed by decapitation. Serum samples were obtained from blood following centrifugation at $4^{\circ} \mathrm{C}, 1,728 \times \mathrm{g}$ for $20 \mathrm{~min}$ and stored at $-20^{\circ} \mathrm{C}$ for detection.

Biochemical assays. The serum levels of total bile acid (TBA), total bilirubin (TBIL), direct bilirubin (DBIL), alanine aminotransferase (ALT), aspartate aminotransferase (AST) and alkaline phosphatase (ALP) were measured using common commercial assay kits (TBA, ALT, AST and ALP kits were obtained from Shanghai Kehua Bio-engineering Co., Ltd.; TBIL and DBIL kits were obtained from Roche Diagnostics) using an automatic biochemical analyzer (Roche Diagnostics) in the clinical laboratory of the First Affiliated Hospital of Anhui Medical University. Hepatic superoxide dismutase (SOD) activity and malondialdehyde (MDA) content were detected in the supernatants from 10\% liver homogenates, which were prepared according to the manufacturer's protocols. SOD and MDA kits were obtained from Nanjing Jiancheng Bioengineering Institute.
Liver histopathology. Liver tissues were embedded in paraffin following fixation in $10 \%$ formalin at room temperature for $24 \mathrm{~h}$. Tissues were subsequently cut into $4-\mu \mathrm{m}$ thick sections $24 \mathrm{~h}$ later, deparaffinized in xylene and hydrated in a graded series of ethanol, and then routinely stained with hematoxylin for $5 \mathrm{~min}$ and eosin for $10 \mathrm{sec}$ at room temperature. From each sample, 5 adjacent, non-overlapping fields were selected at random and observed using routine light microscopy at $x 400$ magnification.

Electrophoretic mobility shift assay (EMSA). EMSA was performed according to the instructions of the Light Shift Chemiluminescent EMSA kit (cat. no. 89880; Thermo Fisher Scientific, Inc.) to detect the DNA binding activity of $\mathrm{NF}-\kappa \mathrm{B}$. Nuclear extracts from liver tissues were prepared using a nuclear extraction kit (Viagene Biotech, Inc.) and quantified using a bicinchoninic acid (BCA) protein assay kit (Thermo Fisher Scientific, Inc.). A biotin-labeled NF- $\kappa B$ probe (Santa Cruz Biotechnology, Inc.) with a 5'-AGTTGA GGGGACTTTCCCAGGC-3' sequence and nuclear proteins $(15 \mu \mathrm{g})$ were incubated in a total volume of $15 \mu \mathrm{l}$ in binding buffer at room temperature for $20 \mathrm{~min}$. The extracts were also incubated with specific NF- $\kappa B$ p65 antibody $(2 \mu \mathrm{g} / \mu \mathrm{l}$; cat. no. SC-372X; Santa Cruz Biotechnology, Inc.) at room temperature for $20 \mathrm{~min}$ for a supershift assay. The specificity of binding was detected by competition with unlabeled 100 -fold excess of a cold and a mutant probe with a $5^{\prime}$-TGG GGA ACC TGTGCT GAGTCACTGGAG-3' sequence (Thermo Fisher Scientific, Inc.). Following incubation, the DNA-nuclear protein mixtures $(15 \mu \mathrm{l})$ were subjected to gel electrophoresis on a $6.5 \%$ nondenaturing polyacrylamide gel in $0.25 \mathrm{X}$ Tris-borate-ethylenediaminetetraacetic buffer at $120 \mathrm{~V}$ for $60 \mathrm{~min}$, and then transferred to a presoaked nylon membrane. When the transfer was complete, DNA was cross-linked to the membrane within commercial UA-light for $10 \mathrm{~min}$. The biotinylated DNA-protein bands were detected with streptavidin-horseradish peroxidase (HRP; 1:750) using a Chemiluminescent Assay (Thermo Fisher Scientific, Inc.).

Reverse transcription-polymerase chain reaction (RT-PCR) analysis. Total RNA was extracted from liver tissues using TRIzol reagent (Sangon Biotech Co., Ltd.) according to the manufacturer's instructions. RNA concentration was measured by NanoDrop ${ }^{\mathrm{TM}} 2000$ (NanoDrop Technologies; Thermo Fisher Scientific, Inc.). Then, cDNA was synthesized using a First Strand cDNA Synthesis kit (Sangon Biotech Co., Ltd.), according to the manufacturer's protocol. The reverse transcription system was conducted at a final volume of $20 \mu 1$, including total RNA $(5 \mu \mathrm{l})$, primer mix (1 $\mu \mathrm{l})$, dNTP Mix $(2 \mu \mathrm{l})$, RNase inhibitor $(1 \mu \mathrm{l})$, AMV Reverse Transcriptase $(2 \mu \mathrm{l})$, RNase-free $\mathrm{ddH}_{2} \mathrm{O}(5 \mu \mathrm{l}), 5 \mathrm{X}$ RT buffer $(4 \mu \mathrm{l})$. The PCR system $(25 \mu \mathrm{l})$ comprised cDNA $(0.5 \mu \mathrm{l})$, forward primer $(0.5 \mu \mathrm{l})$, reverse primer $(0.5 \mu \mathrm{l})$, Taq polymerase $(0.2 \mu \mathrm{l}$; Sangon Biotech Co., Ltd.), dNTP (0.5 $\mu \mathrm{l}), 10 \mathrm{X}$ Taq Buffer $(2.5 \mu \mathrm{l}), \mathrm{MgCl}_{2}(2 \mu \mathrm{l})$, RNase-free $\mathrm{ddH}_{2} \mathrm{O}(18.3 \mu \mathrm{l})$. Amplification conditions were as follows: Pre-denaturation at $95^{\circ} \mathrm{C}$ for $3 \mathrm{~min}$, followed by 35 cycles of denaturation at $94^{\circ} \mathrm{C}$ for $30 \mathrm{sec}$, annealing at $56^{\circ} \mathrm{C}$ for $30 \mathrm{sec}$, extension at $72^{\circ} \mathrm{C}$ for $90 \mathrm{sec}$, final extension at $72^{\circ} \mathrm{C}$ for 8 min. Primers were synthesized by Sangon Biotech Co., Ltd. Primer sequences were as follows: Tumor necrosis factor 
(TNF)- $\alpha$, forward 5'-GTCGTAGCAAACCACCAAGC-3', reverse 5'-TCACAGAGCAATGACTCCAAAG-3'; bile salt export pump (BSEP), forward 5'-GCACAGTTGCTGGGA TTGG-3', reverse 5'-TTGGCATAGCTCGGAGTATAAGA-3'; $\beta$-actin, forward 5'-GCACAGTTGCTGGGATTGG-3' and reverse 5'-TTGGCATAGCTCGGAGTATAAGA-3'.

All PCR products were examined by gel electrophoresis and visualized by ethidium bromide staining. The analysis of PCR products was performed using a gel documentation system (Shanghai Furi Technology Co., Ltd.).

Western blot analysis. Liver tissues was homogenized and centrifuged at a speed of $14,917 \mathrm{x}$ g for $15 \mathrm{~min}$ at $4^{\circ} \mathrm{C}$. Total proteins of liver tissues were extracted using RIPA lysate with PMSF (both Beyotime Institute of Biotechnology). After the protein concentration in the supernatants was measured using a BCA protein assay kit (Beyotime Institute of Biotechnology), the protein samples were mixed with 5X SDS loading buffer at a ratio of $1: 4$, then denatured at $95^{\circ} \mathrm{C}$ for $10 \mathrm{~min}$. Equal amounts of protein $(30 \mu \mathrm{g})$ were separated via $12 \%$ SDS-PAGE and transferred to polyvinylidene fluoride membranes (EMD Millipore). Following incubation with blocking buffer (5\% nonfat milk) for $2 \mathrm{~h}$ at room temperature, membranes were incubated overnight at $4^{\circ} \mathrm{C}$ with rabbit anti-BSEP (1:500; cat. no. BS71760; Bioworld Technology, Inc.) and anti- $\beta$-actin (1:1,000; cat. no. TA-09; OriGene Technologies, Inc.) primary antibodies, then washed with TBST and incubated with an HRP-coupled secondary antibody (1:10,000; cat. no. ZB-2301; Beijing Zhongshan Golden Bridge Biotech Co., Ltd; OriGene Technologies, Inc.) for $1 \mathrm{~h}$ at room temperature. The immunoblots were rinsed extensively with TBS-Tween $20(0.1 \%)$ and visualized using an ECL western blot detection kit (Thermo Fisher Scientific, Inc.). Signals were normalized to $\beta$-actin levels, which was used as the internal standard. Semi-quantitative evaluation was performed by densitometry using ImageJ software (version 1.51; National Institutes of Health).

Statistical analysis. SPSS software (version 22.0; IBM Corp.) was used for the statistical analysis. All data are presented as the mean \pm SD. Statistical analysis of the differences between groups was performed using one-way analysis of variance (ANOVA) followed by Student Newman-Keuls test as post hoc. $\mathrm{P}<0.05$ was considered to indicate a statistically significant difference.

\section{Results}

PDTC treatment ameliorates general performance in INH/RIF-induced liver injury. There was no mortality in any of the groups. Rats in the INH + RIF group showed loss of appetite, listlessness, rough hair coat and slow response to external stimuli compared with the control group. In addition, the skin and mucous membrane of the nose, ears, paws and tail were dyed orange. Feces and urine were also clearly orange. The general behavior of the rats in the PDTC group was almost the same as that of control rats.

PDTC attenuates INH /RIF-induced liver injury. Intraperitoneal administration of INH and RIF at a dose of $50 \mathrm{mg} / \mathrm{kg} /$ day over a period of 28 days produced hepatotoxicity.
As presented in Table I, the co-administration of INH and RIF significantly increased serum TBA, TBIL, DBIL and ALP activity compared with the control $(\mathrm{P}<0.01)$. There were no significant alterations in the levels of ALT and AST $(\mathrm{P}>0.05)$, whereas PDTC treatment significantly attenuated the elevation of serum TBA, TBIL, DBIL and ALP compared with the INH + RIF group $(\mathrm{P}<0.01)$, which was suggestive of reduced injury in liver tissues (Table I). Next, as presented in Fig. 1, all animals in the control group showed normal morphology (Fig. 1A). The INH + RIF group exhibited moderate to severe lobular inflammation and piecemeal necrosis (Fig. 1B). The liver histology of the PDTC group exhibited an almost normal morphology, with only a low level of liver steatosis and occasional infiltration of inflammatory cells (Fig. 1C). Liver histopathology was consistent with serum biochemistry in the present study.

PDTC treatment alleviates INH/RIF-induced oxidative stress. To evaluate the protective effects of PDTC against INH/RIF-induced oxidative stress, SOD activity and MDA content in liver tissue were detected. The SOD activity in liver homogenates was significantly decreased in the INH + RIF group compared with the control $(\mathrm{P}<0.01)$. However, the administration of PDTC significantly attenuated the INH/RIF-induced reduction in SOD activity $(\mathrm{P}<0.01)$. Similarly, the MDA content was significantly elevated following co-administration of INH and RIF as compared with the control group $(\mathrm{P}<0.01)$, whereas PDTC treatment effectively decreased the INH/RIF-induced increase in MDA content ( $\mathrm{P}<0.01$; Fig. 2).

PDTC inhibits INH/RIF-induced NF- $\kappa B$ activation. EMSA was used to further explore the potential role of NF- $\mathrm{KB}$ in INH/RIF-induced liver injury. Following the co-administration of INH and RIF, the NF- $\mathrm{kB}$ DNA-binding activity of liver homogenates was upregulated significantly $(\mathrm{P}<0.01)$; PDTC treatment markedly inhibited INH/RIF-induced NF- $\mathrm{KB}$ activity ( $\mathrm{P}<0.01$; Fig. $3 \mathrm{~A}$ and $\mathrm{B})$. Furthermore, supershift analysis using p65 antibody against NF- $\kappa \mathrm{B}$ demonstrated that the band was in accordance with the p65 NF- $\mathrm{KB}$ subunit (Fig. 3A). These results suggested that NF- $\mathrm{KB}$ activation was involved in the pathogenesis of INH and RIF-induced liver injury.

PDTC prevents INH/RIF-induced upregulation of TNF- $\alpha$ and downregulation BSEP. To further study the possible mechanisms via which PDTC alleviates INH and RIF-induced liver injury, the levels of TNF- $\alpha$ and BSEP mRNA gene expression were detected in liver tissues via RT-PCR, and the protein expression of BSEP was detected via western blot analysis. Compared with the control group, the mRNA expression of TNF- $\alpha$ and BSEP was significantly up- and downregulated, respectively, in the INH + RIF group (both $\mathrm{P}<0.01$; Fig. 4A and B), and the protein expression of BSEP was also significantly decreased in the INH + RIF group $(\mathrm{P}<0.01$; Fig. 5A and B). Conversely, compared with the INH + RIF group, the mRNA expression of TNF- $\alpha$ and BSEP was significantly decreased and increased, respectively, in the PDTC group $(\mathrm{P}<0.01$ and $\mathrm{P}<0.05$, respectively; Fig. $4 \mathrm{~A}$ and $\mathrm{B})$, and the protein expression of BSEP was also significantly elevated in the PDTC group $(\mathrm{P}<0.01$; Fig. 5A and $\mathrm{B})$. These results 
Table I. PDTC attenuates liver functional damage induced by INH and RIF.

Parameters $($ mean \pm SD)

\begin{tabular}{lccccccc}
\cline { 3 - 7 } Group & $\mathrm{N}$ & $\mathrm{TBA}(\mu \mathrm{mol} / \mathrm{l})$ & TBIL $(\mu \mathrm{mol} / \mathrm{l})$ & DBIL $(\mu \mathrm{mol} / \mathrm{l})$ & ALP $(\mathrm{U} / \mathrm{l})$ & ALT $(\mathrm{U} / \mathrm{l})$ & AST (U/l) \\
\hline Control & 8 & $22.13 \pm 2.70$ & $1.02 \pm 0.13$ & $0.22 \pm 0.07$ & $82.00 \pm 8.38$ & $42.34 \pm 5.77$ & $137.21 \pm 12.28$ \\
INH + RIF & 8 & $44.26 \pm 7.75^{\mathrm{a}}$ & $3.80 \pm 0.74^{\mathrm{a}}$ & $2.40 \pm 0.58^{\mathrm{a}}$ & $117.88 \pm 17.59^{\mathrm{a}}$ & $43.05 \pm 11.56$ & $146.29 \pm 18.53$ \\
PDTC & 8 & $22.56 \pm 4.08^{\mathrm{b}}$ & $2.20 \pm 0.44^{\mathrm{b}}$ & $1.20 \pm 0.21^{\mathrm{b}}$ & $93.00 \pm 10.07^{\mathrm{b}}$ & $20.32 \pm 4.61$ & $114.32 \pm 9.79$ \\
\hline
\end{tabular}

${ }^{\mathrm{a}} \mathrm{P}<0.01$ vs. Control; ${ }^{\mathrm{b}} \mathrm{P}<0.01$ vs. INH + RIF. INH, isoniazid; RIF, rifampicin; PDTC, pyrrolidine dithiocarbamate; ALT, alanine aminotransferase; AST, aspartate aminotransferase; ALP, alkaline phosphatase; TBA, total biliary acid; TBIL, total bilirubin; DBIL, direct bilirubin.
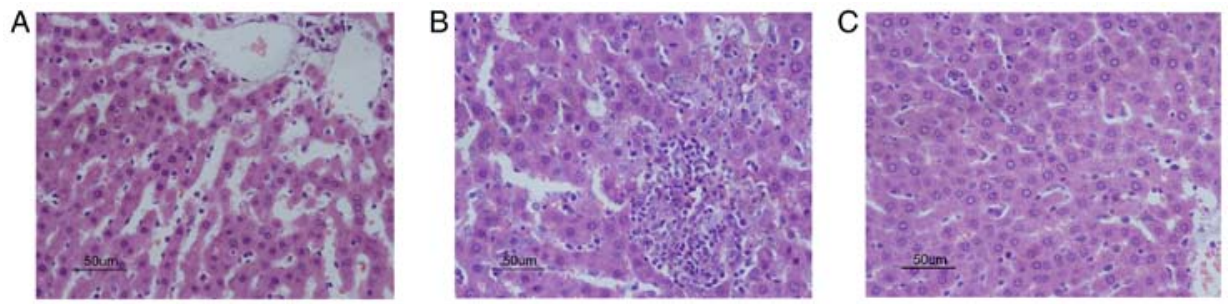

Figure 1. PDTC treatment improves hepatic injury induced by INH + RIF. Hematoxylin and eosin staining (magnification, $\mathrm{x} 400$ ). (A) Control group. (B) INH + RIF group. (C) PDTC group. PDTC, pyrrolidine dithiocarbamate; INH, isoniazid; RIF, rifampicin.

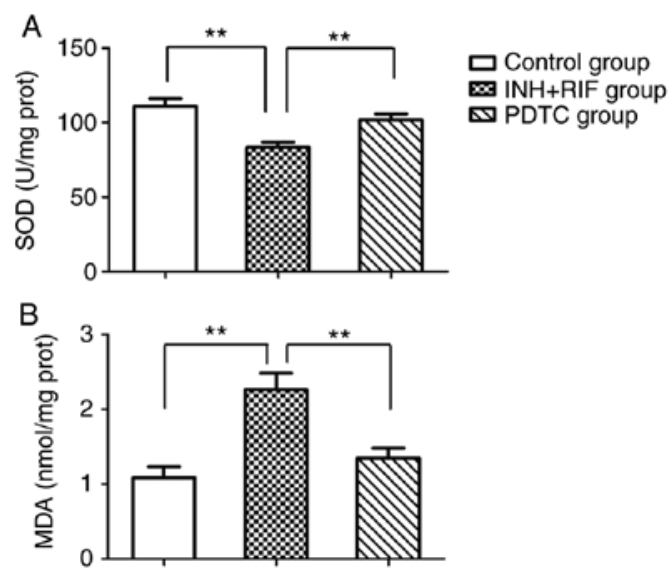

Figure 2. Effects of PDTC on MDA content and SOD activity in INH/RIF-treated rats. (A) SOD activity. (B) MDA content. ${ }^{* *} \mathrm{P}<0.01$. PDTC, pyrrolidine dithiocarbamate; MDA, malondialdehyde; SOD, superoxide dismutase; INH, isoniazid; RIF, rifampicin.

revealed that PDTC could prevent INH/RIF-induced increases in TNF- $\alpha$ and decreases in BSEP.

\section{Discussion}

Liver injury is a highly prevalent clinical disease worldwide, with its main types being viral hepatitis, drug-induced liver injury (DILI), alcoholic liver disease, hepatic ischemia-reperfusion injury, non-alcoholic fatty liver disease, hepatocellular carcinoma and hepatic parasitic diseases (18-20). Drug-related hepatotoxicity is one of the main challenges faced by clinicians, as it is a major cause of liver failure characterized by morphological and
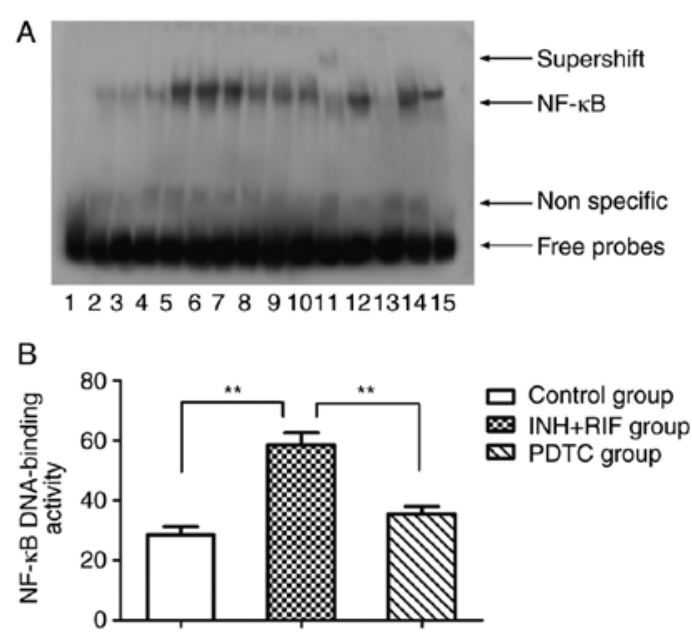

Figure 3. NF- $\kappa \mathrm{B}$ DNA-binding activity of rat livers by EMSA (A) Representative autoradiogram for each group. Channel 1, negative control; channels 2-4, control group; channels 5-7, INH + RIF group; channels 8-10, PDTC group; channel 11, nuclear extracts incubated with anti-p65 antibody; channel 12, negative control of P65 antibody; channel 13, cold competition control with a 100 -fold excess of unlabeled probe; channel 14 cold competition control with a 100 -fold excess of unlabeled mutant probe; channel 15, positive control of NF- $\kappa \mathrm{B}$ activity. (B) Relative amount of

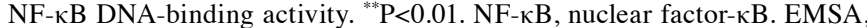
Electrophoretic mobility shift assay; INH, isoniazid; RIF, rifampicin; PDTC, pyrrolidine dithiocarbamate.

metabolic aberrations in the liver, owing to the fact that the liver is the main drug detoxification organ (5). In the present study, the co-administration of INH and RIF $(50 \mathrm{mg} / \mathrm{kg} / \mathrm{day}$ for 28 days) successfully induced a hepatotoxic model of drug-induced liver injury in rats characterized by the elevation of serum markers, hepatocellular steatosis, 

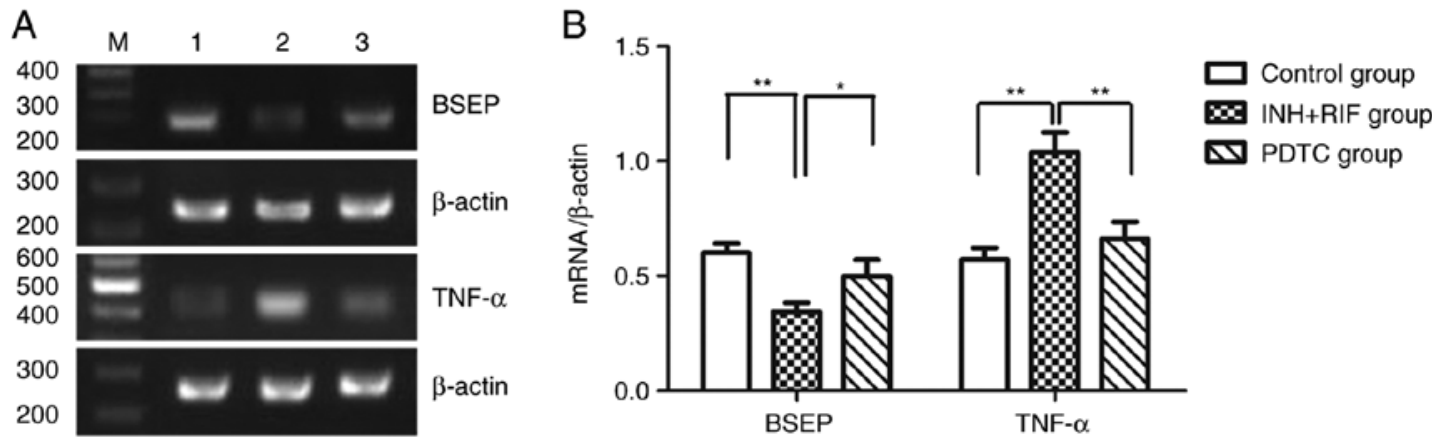

Figure 4. Effects of PDTC on the mRNA expression of BSEP and TNF- $\alpha$ in liver tissues, as determined via reverse transcription-PCR. (A) Representative autoradiogram results. 1, control group; 2, INH + RIF group; 3, PDTC group. (B) Ratio of BSEP and TNF- $\alpha$ normalized to the $\beta$-actin mRNA level. "P<0.05, ${ }^{* *} \mathrm{P}<0.01$. INH, isoniazid; RIF, rifampicin; PDTC, pyrrolidine dithiocarbamate; BSEP, bile salt export pump; TNF, tumor necrosis factor.

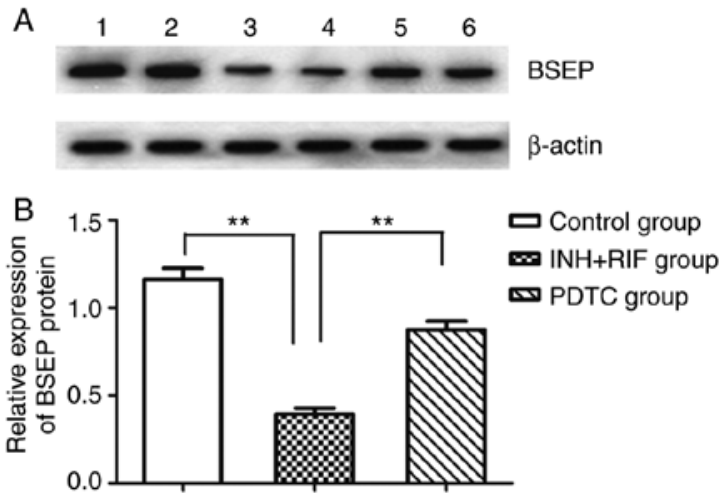

Figure 5. Effect of PDTC on the protein expression of BSEP in the liver tissues, as determined via western blot analysis. (A) Representative western blots for BSEP protein. 1 and 2, Control group; 3 and 4, INH + RIF group; 5 and 6, PDTC group. (B) BSEP was normalized to the $\beta$-actin protein level. ${ }^{* *} \mathrm{P}<0.01$. PDTC, pyrrolidine dithiocarbamate; BSEP, bile salt export pump; INH, isoniazid; RIF, rifampicin.

inflammatory cell infiltration, and spotty and focal necrosis, consistent with previous studies $(13,14,21)$.

$\mathrm{NF}-\mathrm{KB}$ activation has been implicated in the pathogenesis of hepatocyte injury in a series of experimental models of liver damage $(9-12,16)$, suggesting that the inhibition of $\mathrm{NF}-\kappa \mathrm{B}$ could serve as a potential protective candidate against various types of liver disease. The present study demonstrated that NF-kB was markedly activated by INH + RIF. PDTC treatment protected against INH-RIF-induced liver injury by attenuating increases in serum TBA, TBIL, DBIL and ALP levels, and improving histopathological changes. These results suggested a protective effect of PDTC against anti-TB drug-induced liver injury. The results also showed that the PDTC group exhibited a lower level of ALT and AST than the control group; however, this was not significant. A previous study reported that the level of ALT was lower in a PDTC group compared with a control group in a rat model of liver injury induced by intestinal ischemia-reperfusion, which is a similar result to the present study (22). However, to the best of the authors' knowledge, no study has yet elucidated the specific mechanism underlying this phenomenon. Therefore, the results should be interpreted with caution, due to the limited number of reports, and further large-scale, well-designed randomized controlled trials on this topic are required.
Previous studies have shown that oxidative stress serves an important role in the pathogenesis of INH-RIF-induced liver injury $(21,23)$, which is generally attributed to the accumulation of ROS, also known as a secondary messenger to activate NF- $\kappa B(24,25)$. The present study showed that hepatic SOD activity was markedly decreased following INH + RIF administration. Furthermore, the hepatic MDA content was significantly elevated, supporting previous observations that oxidative stress may play a partial role in INH and RIF-induced liver injury.

PDTC exerts direct antioxidant effects by inhibiting free radical generation and scavenging free radicals via its chelating activity for metal ions, which may catalyze the formation of free radicals (26). Additionally, PDTC has been shown to alleviate oxidative injury via the inhibition of oxidative stress in drug-induced hepatic fibrosis, drug-induced acute kidney injury and gastroesophageal reflux disease in experimental models $(9,27,28)$. In the present study, it was observed that PDTC administration significantly reversed the reduction in SOD activity and attenuated the elevation of the MDA level. These results indicated that PDTC might protect against INH/RIF-induced liver injury via its antioxidant effects.

A growing body of evidence has indicated that TNF- $\alpha$ plays an important role in the pathogenesis of DILI by mediating direct hepatocyte injury and accelerating inflammatory cytokine production (29). TNF- $\alpha$ binding to the TNF receptor initiates NF- $\mathrm{KB}$ activation, inducing the expression of inflammatory genes and the release of a large number of inflammatory factors (30). In addition, TNF- $\alpha$ has been shown to result in ROS generation, mainly through mitochondrial pathways or NADPH oxidase $(31,32)$, which upregulate inflammatory cascades and promote liver injury. Results from the present study showed that a marked inflammatory response in INH and RIF-induced liver injury, demonstrated by inflammatory cell infiltration, markedly activated hepatic NF- $\kappa B$ and upregulated hepatic TNF- $\alpha$ mRNA. These results indicated that the NF- $\mathrm{kB}$-mediated upregulation of TNF- $\alpha$ may be involved in the pathogenesis of INH/RIF-induced liver injury. Several studies have shown that PDTC can prevent inflammatory injury via the inhibition of NF- $\kappa \mathrm{B}$ and the subsequent downregulation of TNF- $\alpha(27,33)$. In the present study, it was found that the administration of PDTC reduced inflammation, suppressed NF- $\mathrm{KB}$ activation and resulted in 
the downregulation of TNF- $\alpha$ mRNA, indicating that the anti-inflammatory action of PDTC partially contributed to liver protection.

In the present study, it was observed that the INH/RIF-induced clinical liver dysfunction of rats predominantly manifested as increased levels of TBA, TBIL, DBIL and ALP, which indicated a cholestatic DILI (34). It has been reported that cholestatic liver injury may be associated with impaired hepatobiliary transporters expressed at the apical membrane of hepatocytes (35). BSEP, an ATP-binding cassette transporter encoded by the $A B C B 11$ gene, is primarily localized on the canalicular membrane of hepatocytes and regulates conjugated bile acid excretion, as well as hepatic excretion of various forms of drugs and their metabolites into bile (36). The inhibition of BSEP activity could lead to decreased biliary excretion, accumulation of bile salts inside hepatocytes and cholestatic liver disease (37). It has been reported that RIF is a competitive inhibitor of BSEP (38). An in vitro study also demonstrated that anti-TB drug administration markedly downregulated hepatogenic BSEP (39). Results from the present study were consistent with previous reports, showing a reduction in BSEP coupled with decreased levels of TBA, TBIL, DBIL and ALP in INH + RIF-treated rats, which implied that the inhibition of BSEP resulting in the disruption of bile acid homeostasis may be a potential mechanism underlying INH/RIF-induced liver injury. PDTC treatment markedly upregulated BSEP and reversed the elevation of serum markers. These results suggested that PDTC may protect against INH/RIF-induced hepatic injury by increasing the expression of BSEP. However, the underlying mechanisms of PDTC-induced BSEP upregulation remain poorly understood.

It has previously been indicated that inflammation plays a crucial role in cholestatic liver injury (40). Certain studies have suggested that BSEP expression can be reduced by proinflammatory cytokines activating specific signaling pathways during inflammation (41-43). In the present study, it was found that TNF- $\alpha$ was markedly elevated when NF- $\mathrm{KB}$ was activated in INH and RIF-treated rats with a concurrent decrease in BSEP expression, indicating a possible crosstalk between BSEP and the NF- $\mathrm{kB} / \mathrm{TNF}-\alpha$ signaling pathways. These data were consistent with the hypothesis that inflammation leads to the downregulation of BSEP, and that the restoration of its expression by inhibiting inflammation in the liver may re-establish bile acid homeostasis (44). PDTC therapy may therefore upregulate the expression of BSEP and improve cholestasis by controlling inflammatory pathways as a result of NF- $\kappa \mathrm{B}$ inhibition.

In conclusion, the findings of the present study indicated that PDTC exerted protective effects against INH/RIF-induced hepatic injury. The anti-inflammatory and antioxidant effects, as well as upregulation of BSEP, may underlie the therapeutic actions of PDTC in the treatment of INH/RIF-induced liver injury. Moreover, it is important to investigate whether these experimental observations can be validated in liver cell models. Therefore, future studies will focus on the effect of PDTC on anti-TB-drug-induced liver injury in vitro.

\section{Acknowledgements}

Not applicable.

\section{Funding}

This work was funded by Natural Science Foundation of Anhui Province (grant no. 1208085MH155).

\section{Availability of data and materials}

The datasets used and/or analyzed during the current study are available from the corresponding author on reasonable request.

\section{Authors' contributions}

$\mathrm{XH}$ was involved in the acquisition and analysis of data, and drafting the article. YS contributed to the experimental design, the interpretation of data, revising the manuscript, and supervision and guidance. LW was involved in the acquisition and analysis of data. JX contributed to the experimental design, revised the manuscript and provided supervision and guidance. All authors read and approved the final manuscript.

\section{Ethics approval and consent to participate}

All experimental procedures for treating animals in this study were performed according to National Regulations on the Administration of Laboratory Animals and approved by the Animal Care and Use Committee of Anhui Medical University.

\section{Patient consent for publication}

Not applicable.

\section{Competing interests}

The authors declare that they have no competing interests.

\section{References}

1. World Health Organization: Global tuberculosis report 2015. World Health Organization, Geneva, 2015.

2. Yew WW and Leung CC: Antituberculosis drugs and hepatotoxicity. Respirology 11: 699-707, 2006

3. Yew WW, Chang KC and Chan DP: Oxidative stress and first-line antituberculosis drug-induced hepatotoxicity. Antimicrob Agents Chemother 62: e02637-17, 2018.

4. Baskaran UL and Sabina EP: Clinical and experimental research in antituberculosis drug-induced hepatotoxicity: A review. J Integr Med 15: 27-36, 2017.

5. Santhosh S, Sini TK, Anandan R and Mathee PT: Hepatoprotective activity of chitosan against isoniazid and rifampicin-induced toxicity in experimental rats. Eur J Pharmacol 572: 69-73, 2007.

6. Chowdhury A, Santra A, Bhattacharjee K, Ghatak S, Saha DR and Dhali GK: Mitochondrial oxidative stress and penneability transition in isoniaizd and Rifampicin induced liver injury in mice. J Hepatol 45: 117-126, 2006.

7. Nicoletti NF, Rodrigues-Junior V, Santos AA Jr, Leite CE, Dias AC, Batista EL Jr, Basso LA, Campos MM, Santos DS and Souto AA: Protective effects of resveratrol on hepatotoxicity induced by isoniazid and rifampicin via SIRT1 modulation. J Nat Prod 77: 2190-2195, 2014

8. Leotoing L, Chereau F, Baron S, Hube F, Valencia HJ, Bordereaux D, Demmers JA, Strouboulis J and Baud V: A20-binding inhibitor of nuclear factor-kappaB (NF-kappaB)-2 (ABIN-2) is an activator of inhibitor of NF-kappaB (IkappaB) kinase alpha (IKKalpha)-mediated NF-kappaB transcriptional activity. J Biol Chem 286: 32277-32288, 2011. 
9. Bruck R, Schey R, Aeed H, Hochman A, Genina O and Pines M A protective effect of pyrrolidine dithiocarbamate in a rat model of liver cirrhosis. Liver Int 24: 169-176, 2004.

10. Qin JD, Cao ZH, Li XF, Kang XL, Xue Y, Li YL, Zhang D, Liu XY and Xue YZ: Effect of ammonium pyrrolidine dithiocarbamate (PDTC) on NF- $\kappa$ B activation and CYP2E1 content of rats with immunological liver injury. Pharm Biol 52: 1460-1466, 2014

11. Yang $F$, Li X, Wang LK, Wang LW, Han XQ, Zhang $\mathrm{H}$ and Gong ZJ: Inhibitions of NF- $\kappa \mathrm{B}$ and TNF- $\alpha$ result in differential effects in rats with acute on chronic liver failure induced by d-Gal and LPS. Inflammation 37: 848-857, 2014.

12. Demirbilek S, Akin M, Gürünlüoğlu K, Aydin NE, Emre MH Tas E, Aksoy RT and Ay S: The NF-kappaB inhibitors attenuate hepatic injury in bile duct ligated rats. Pediatr Surg Int 22: 655-663, 2006

13. Rana SV, Pal R, Vaiphie K and Singh K: Effect of different oral doses of isoniazid-rifampicin in rats. Mol Cell Biochem 289: 39-47, 2006.

14. Pal R, Vaiphei K, Sikander A, Singh K and Rana SV: Effect of garlic on isoniazid and rifampicin-induced hepatic injury in rats. World J Gastroenterol 12: 636-639, 2006.

15. Matsui N, Kasajima K, Hada M, Nagata T, Senga N, Yasui Y, Fukuishi $\mathrm{N}$ and Akagi M: Inhibiton of NF-kappaB activation during ischemia reduces hepatic ischemia/reperfusion injury in rats. J Toxicol Sci 30: 103-110, 2005.

16. Heiman J, Wallin M, Gustafsson BI, Friman S and Delbro D Pharmacological of rat liver by up-regulation of heme oxygenase 1. Transplant Proc 38: 2705-2707, 2006.

17. Pan M, Song YL, Xu JM and Gan HZ: Melatonin ameliorates nonalcoholic fatty liver induced by high-fat diet in rats. J Pineal Res 41: 79-84, 2006.

18. Wang FS, Fan JG, Zhang Z, Gao B and Wang HY: The global burden of liver disease: The major impact of China. Hepatology 60: 2099-2108, 2014.

19. Işık A, Fırat D, Korkmaz S, Demiryılmaz İ and Yılmaz İ: Atipik prezente kist hidatik: Pankreas Başında Kitle. Sakarya Tıp Dergisi 8: 149-152, 2018.

20. Iş1k A, Sayar İ, Gülhan B and Firat D: Fascioliasis: A rare case mimicking cholelithiasis. J Kartal TR 27: 145-146, 2016.

21. Sodhi CP, Rana SV, Mehta SK, Vaiphei K, Attari S and Mehta S: Study of oxidative-stress in isoniazid-rifampicin induced hepatic injury in young rats. Drug Chem Toxicol 20: 255-269, 1997.

22. Tian XF, Yao JH, Li YH, Gao HF, Wang ZZ, Yang CM and Zheng SS: Protective effect of pyrrolidine dithiocarbamate on liver injury induced by intestinal ischemia-reperfusion in rats. Hepatobiliary Pancreat Dis Int 5: 90-95, 2006.

23. Rana SV, Pal R, Vaiphei K, Ola RP and Singh K: Hepatoprotection by carotenoids in isoniazid-rifampicin induced hepatic injury in rats. Biochem Cell Biol 88: 819-834, 2010.

24. Narayanan A, Amaya M, Voss K, Chung M, Benedict A, Sampey G, Kehn-Hall K, Luchini A, Liotta L, Bailey C, et al: Reactive oxygen species activate $\mathrm{NF \kappa B}(\mathrm{p} 65)$ and $\mathrm{p} 53$ and induce apoptosis in RVFV infected liver cells. Virology 449: 270-286, 2014

25. Kastl L, Sauer SW, Ruppert T, Beissbarth T, Becker MS, Süss D, Krammer PH and Gülow K: TNF- $\alpha$ mediates mitochondrial uncoupling and enhances ROS-dependent cell migration via NF- $\kappa B$ activation in liver cells. FEBS Lett 588: 175-183, 2014.

26. Lu JW, Wang H, Yan-Li J, Zhang C, Ning H, Li XY, Zhang H, Duan ZH, Zhao L, Wei W and Xu DX: Differential effects of pyrrolidine dithiocarbamate on TNF-alpha-mediated liver injury in two different models of fulminant hepatitis. J Hepatol 48 442-452, 2008

27. Yu HX, Wang XL, Zhang LN, Zhang J and Zhao W: Involvement of the TLR4/NF- $\kappa B$ signaling pathway in the repair of esophageal mucosa injury in rats with gastroesophageal reflux disease. Cell Physiol Biochem 51: 1645-1657, 2018.
28. Borghi SM, Fattori V, Ruiz-Miyazawa KW, Bertozzi MM, Lourenco-Gonzalez Y, Tatakihara RI, Bussmann AJC, Mazzuco TL, Casagrande R and Verri WA Jr: Pyrrolidine dithiocarbamate inhibits mouse acute kidney injury induced by diclofenac by targeting oxidative damage, cytokines and NF- $\kappa \mathrm{B}$ activity. Life Sci 208: 221-231, 2018.

29. Masson MJ, Collins LA and Pohl LR: The role of cytokines in the mechanism of adverse drug reactions. Handb Exp Pharmacol: 195-231, 2010 doi: 10.1007/978-3-642-00663-0_8.

30. Blaser H, Dostert C, Mak TW and Brenner D: TNF and ROS crosstalk in inflammation. Trends Cell Biol 26: 249-261, 2016.

31. Morgan MJ and Liu ZG: Reactive oxygen species in TNFalpha-induced signaling and cell death. Mol Cells 30: 1-12, 2010.

32. Moe KT, Khairunnisa K, Yin NO, Chin-Dusting J, Wong P and Wong MC: Tumor necrosis factor- $\alpha$-induced nuclear factor-kappaB activation in human cardiomyocytes is mediated by NADPH oxidase. J Physiol Biochem 70: 769-779, 2014.

33. He CY, Jiang LP, Wang CY and Zhang Y: Inhibition of NF- $\kappa B$ by pyrrolidine dithiocarbamate prevents the inflammatory response in a ligature-induced peri-implantitis model: A canine study. Cell Physiol Biochem 49: 610-625, 2018.

34. Padda MS, Sanchez M, Akhtar AJ and Boyer JL: Drug-induced cholestasis. Hepatology 53: 1377-1387, 2011.

35. Corsini A and Bortolini M: Drug-induced liver injury: The role of drug metabolism and transport. J Clin Pharmacol 53: 463-474, 2013.

36. Kubitz R, Dröge C, Kluge S, Stindt J and Häussinger D: Genetic variations of bile salt transporters. Drug Discov Today Technol 12: e55-e67, 2014.

37. Kis E, Ioja E, Rajnai Z, Jani M, Méhn D, Herédi-Szabó K and Krajcsi P: BSEP inhibition: In vitro screens to assess cholestatic potential of drugs. Toxicol In Vitro 26: 1294-1299, 2012.

38. Stieger B: The role of the sodium-taurocholate cotransporting polypeptide (NTCP) and of the bile salt export pump (BSEP) in physiology and pathophysiology of bile formation. Handb Exp Pharmacol: 205-259, 2011 doi: 10.1007/978-3-642-14541-4_5.

39. Guo YX, Xu XF, Zhang QZ, Li C, Deng Y, Jiang P, He LY and Peng WX: The inhibition of hepatic bile acids transporters Ntcp and Bsep is involved in the pathogenesis of isoniazid/rifampicin-induced hepatotoxicity. Toxicol Mech Methods 25: 382-387, 2015.

40. Sato K, Hall C, Glaser S, Francis H, Meng F and Alpini G: Pathogenesis of kupffer cells in cholestatic liver injury. Am J Pathol 186: 2238-2247, 2016.

41. Le Vee M, Lecureur V, Stieger B and Fardel O: Regulation of drug transporter expression in human hepatocytes exposed to the proinflammatory cytokines tumor necrosis factor-alpha or interleukin-6. Drug Metab Dispos 37: 685-693, 2009.

42. Donner MG, Schumacher S, Warskulat U, Heinemann J and Häussinger D: Obstructive cholestasis induces TNF-alpha- and IL-1-mediated periportal downregulation of Bsep and zonal regulation of Ntcp, Oatpla4, and Oatp1b2. Am J Physiol Gastrointest Liver Physiol 293: G1134-G1146, 2007.

43. Diao L, Li N, Brayman TG, Hotz KJ and Lai Y: Regulation of MRP2/ABCC2 and BSEP/ABCB11 expression in sandwich cultured human and rat hepatocytes exposed to inflammatory cytokines TNF-\{alpha\}, IL-6, and IL-1\{beta\}. J Biol Chem 285: 31185-31192, 2010.

44. Chen Y, Song X, Valanejad L, Vasilenko A, More V, Qiu X, Chen W, Lai Y, Slitt A, Stoner M, et al: Bile salt export pump is dysregulated with altered farnesoid $\mathrm{X}$ receptor isoform expression in patients with hepatocellular carcinoma. Hepatology 57: $1530-1541,2013$ 